\title{
Varietal responses to soil water deficit: first results from a common- garden vineyard near Bordeaux France
}

\author{
Mark Gowdy ${ }^{1}$, Agnès Destrac-Irvine ${ }^{1}$, Martina Haines ${ }^{1}$, Gregory Gambetta ${ }^{1}$, Philippe Pieri ${ }^{1}$, Elisa Marguerit ${ }^{1}$, \\ Cornelis van Leeuwen ${ }^{1}$
}

${ }^{1}$ UMR EGFV, Bordeaux Sciences Agro, INRA, Univ. Bordeaux, ISVV, 33883 Villenave d'Ornon, France

\begin{abstract}
In wine producing regions around the world, climate change has the potential to decrease the frequency and amount of precipitation and increase average and extreme temperatures. This will both lower soil water availability and increase evaporative demand in vineyards, thereby increasing soil water deficits and associated vine stress. Grapevines control their water status by regulating stomatal closure and other changes to internal plant hydraulics. These responses are complex and have not been clearly characterized across a wide range of different Vitis vinifera varieties. Understanding how vine water status responds to changes in soil water deficits and other variables will help growers modify vineyard design and management practices to meet their quality and yield objectives. Carbon isotope discrimination measurements of certain plant tissues have been shown to provide effective characterization of stomatal closure, while water potential measurements provide a well-proven measure of overall vine water status. Using replicated data collected from an experimental common-garden vineyard at the Institut des Sciences de la Vigne et $d u$ Vin (ISVV) near Bordeaux, France, this project will analyze the effects on carbon isotope discrimination across 39 varieties and water potential across eight varieties against estimates of soil water deficits made using a water balance model running on local meteorology and considering the phenology of each variety. Similar to the literature, preliminary analysis finds as soil water deficit increases, carbon isotope data suggests greater stomatal closure and water potential measurements indicate greater vine stress. For both parameters, analysis will be performed to distinguish any difference in these responses between varieties.
\end{abstract}

\section{Introduction}

In wine producing regions around the world, climate change has the potential to decrease the frequency and amount of precipitation and increase average and extreme temperatures during the growing season. Understanding how vine water status responds to these changes across different Vitis vinifera varieties will help growers modify vineyard design and management practices to meet their quality and yield objectives [1]. Much has been published on how plants regulate water status, but not much to characterize the dynamics of this regulation across the wide range of Vitis vinifera varieties.

As soil water content decreases, the remaining water becomes more tightly bound with the soil matrix and the water potential in the plant must become more negative in order to remove the remaining water and maintain transpiration. In response to this, and other environmental factors, stomata begin to close to moderate water potential and protect the plant from hydraulic failure [2].

As stomata close there is a change in the carbon isotope composition of the carbohydrates and sugars generated by photosynthesis in the leaves at that time. Measurement of the isotope composition $\left(\delta^{13} \mathrm{C}\right)$ in berry juice then provides a useful indication of the level of stomatal closure that existed during the important berryripening period [3]. Water potential measurements collected pre-dawn and mid-day during the berry ripening also provides an assessment of soil water conditions and plant water status during this same period. For estimating the soil water content corresponding to the above measurements, a water balance model was used. Such models can be useful tools when other more costly and intensive methods may be prohibitive [4].

This paper presents preliminary data and analysis characterizing and comparing the stomatal closure response (as indicated by $\delta^{13} \mathrm{C}$ ) for 39 Vitis vinifera varieties; and the plant water status response (as measured by water potential measurements) for eight varieties; both in response to changes in soil water content as estimated by a water balance model. The data presented in this paper was collected from an experimental common-garden vineyard near Bordeaux France, which allows for collection of replicate data [5].

\section{Methods}

\subsection{Experimental vineyard}

The experimental vineyard used for this study was planted in 2009 at the Institute des Sciences de la Vigne et $d u$ Vin (ISVV) situated at the Institut National de la Recherche Agronomique (INRA) domain de la "Grande Ferrade" (33883 Villenave d'Ornon) near Bordeaux, France $\left(44^{\circ} 47^{\prime} 23.83^{\prime \prime} \mathrm{N} 0^{\circ} 34^{\prime} 39.3^{\prime \prime} \mathrm{W}\right)$. It consists of 52 varieties laid out in a randomized block replicate design, with 10 plants of each variety in each of five blocks. This design allows the ability to account for variability in soil or other conditions within the vineyard. 
Vines are pruned double Guyot style with $100 \mathrm{~cm}$ plant x $180 \mathrm{~cm}$ row spacing and trained by vertical shoot positioning with a canopy height of roughly $160 \mathrm{~cm}$. Varieties planted are from the Bordeaux region, as well as other European regions, and some hybrids that might be suitable in Bordeaux in the future as the climate changes. All varieties were planted on $\mathrm{SO} 4$ rootstock clone 761 in gravelly soil typical of the region [5].

Many studies of drought adaptation of plants are carried out in controlled conditions, such as greenhouses, allowing strict control over experimental variables. Fundamental differences between plants in controlled versus field conditions include root distribution and water availability in the profiles of the root zone [6], along with climatic conditions. Hence, experimentation under field conditions is necessary to put results obtained in controlled conditions into perspective [7].

\subsection{Carbon isotope discrimination measurement}

The relative concentration of ${ }^{13} \mathrm{CO}_{2}$ to ${ }^{12} \mathrm{CO}_{2}$ inside the intercellular space of leaves changes relative to that of the atmosphere because of preferential reaction during photosynthesis with ${ }^{12} \mathrm{C}$. These ratios, however, are modified when stomata close and cut off diffusion of $\mathrm{CO}_{2}$ into the intercellular space of the leaves from the atmosphere, causing the sugars formed and incorporated into various plant tissues at that time to contain a modified ratio of carbon isotopes [8]. This makes the measurement of carbon isotope concentration a useful measure of the level of stomatal closure that existed at the time the glucose building blocks of sampled plant tissue or berry juice were photosynthesized [4].

Berries were sampled weekly in 2012 through 2016 from all varieties in all blocks of the vineyard and analyzed for numerous parameters, including sugar concentration, berry weights, and acid content. Afterwards, one sampling date from each season for each variety was selected as representative of full maturity based on sugar content and titratable acidity of the juice and cluster sanitary status. Previously frozen samples from the selected date were then defrosted and one sample per variety per block was prepared for analysis. The ratio of ${ }^{13} \mathrm{CO}_{2}$ to ${ }^{12} \mathrm{CO}_{2}$ was determined in the laboratory by elemental analysis coupled to an isotopic mass spectrometer and reported as a ratio $\times 10^{-3}(\%)$ with less negative values indicating more stomatal closure [9].

Of those originally planted in 2009, 48 varieties are now consistently producing enough fruit for analysis each year, however, only 39 varieties produced enough fruit to perform the various analyses across all five years (2012 through 2016) in this analysis. Data from measurements collected in 2017 are currently being analyzed and measurements will be collected again in 2018 .

\subsection{Water potential measurements}

In order for a vine to continue transpiring, its water potential must become more negative as it overcomes decreasing soil water potential and conductivity in a drying soil [9]. Predawn leaf water potential is considered a good measure of the equilibrium reached in the plant with this water potential in the root zone [11].
Eight varieties in the experimental vineyard (Cabernet-Sauvignon, Merlot, Petit Verdot, Grenache, Tempranillo, Touriga nacional, Sauvignon blanc, and Semillon) were selected from the experimental vineyard for water potential measurement starting in 2017, with the intent of covering a range of varietal stomatal closure tendencies as described in various literature.

Midday leaf, midday stem, and predawn leaf water potential measurements were each made on leaves taken from two vines in each of four vineyard blocks for a total of eight vines per variety, totaling 64 for each water potential measurement. Measurements were performed using standard pressure chamber techniques [11].

\subsection{Water balance modeling}

A water balance model [12] was used to estimate daily soil water content in the vineyard for years 2012 through 2017 for comparison against $\delta^{13} \mathrm{C}$ and water potential measurements. Inputs to the water balance model include phenology, canopy characteristics (dimensions, porosity, orientation), hedging dates, climate (solar radiation, reference evapotranspiration, temperature, precipitation), and an estimate of $160 \mathrm{~mm}$ for total transpirable soil water (TTSW) in the vine root zone. The model then outputs an estimate of soil water content as a fraction of total transpirable soil water (FTSW) on a daily time step. From this the average fraction of total transpirable soil water during the berry-ripening period $\left(\mathrm{FTSW}_{\mathrm{BR}}\right)$ is calculated between dates of véraison and $75 \%$ of berry sugar accumulation for each variety. This averaging period was initially thought by the authors to correspond well with soil water content during berry sugar accumulation, but other averaging methods are being investigated as analysis continues.

\section{Results}

\subsection{Water balance modeling}

A box plot of average FTSW $_{\text {BR }}$ across all varieties for a given year shows 2012 and 2016 having significantly lower soil water content during the berry-ripening period than 2013 through 2015 (Figure 1). A plot of 2017 model output was not included as phenology and carbon isotope data are still under evaluation. FTSW estimates for 2017, however, were used for comparison against predawn water potential measurements. Absolute values of FTSW are likely underestimated due to difficulty estimating TTSW. Also, the model does not account for varietal differences in horizontal root system distribution. Overall, however, resulting relative differences between varieties remain valid.

\subsection{Carbon isotope discrimination response}

A box plot by year of the $\delta^{13} \mathrm{C}$ measurements on berry juice across all varieties for a given year shows significant difference between both 2012 and 2016 when compared to 2013 through 2015 (Figure 2). Similarly, a comparison back with Figure 1 finds overall less negative $\delta^{13} \mathrm{C}$ values (more stomatal closure) in the same years 2012 and 2016, which experienced lower FTSW BR $_{\text {(drier }}$ soil conditions during berry-ripening). 


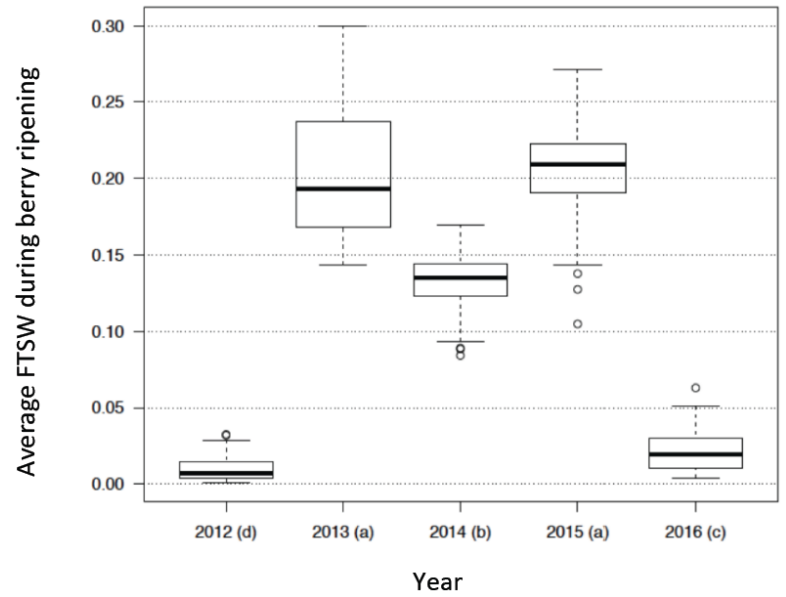

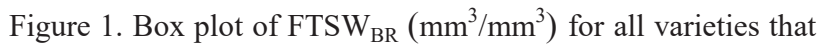
year for 2012 through 2016. Years grouped based Tukey Honest Significant Difference test at $\alpha=0.05$. Dark bar is median; box ends are 75th / 25th percentiles; upper/lower horizontal lines are maximum/minimum respectively, with circles being outliers.

Figure 2. Box plot of $\delta^{13} \mathrm{C}(\%)$ for all varieties measured for

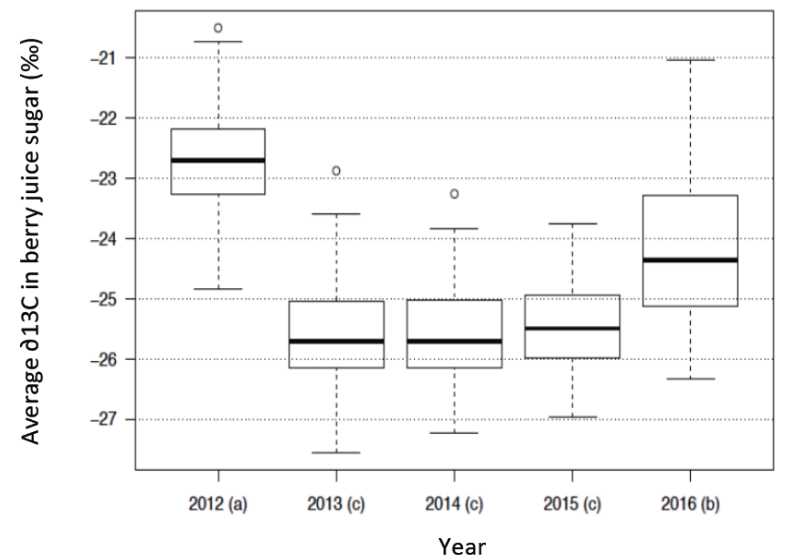

2012 through 2016. Years grouped based Tukey Honest Significant Difference test at $\alpha=0.05$. Dark bar is median; box ends are 75th / 25th percentiles; upper/lower horizontal lines are maximum/minimum respectively, with circles being outliers.

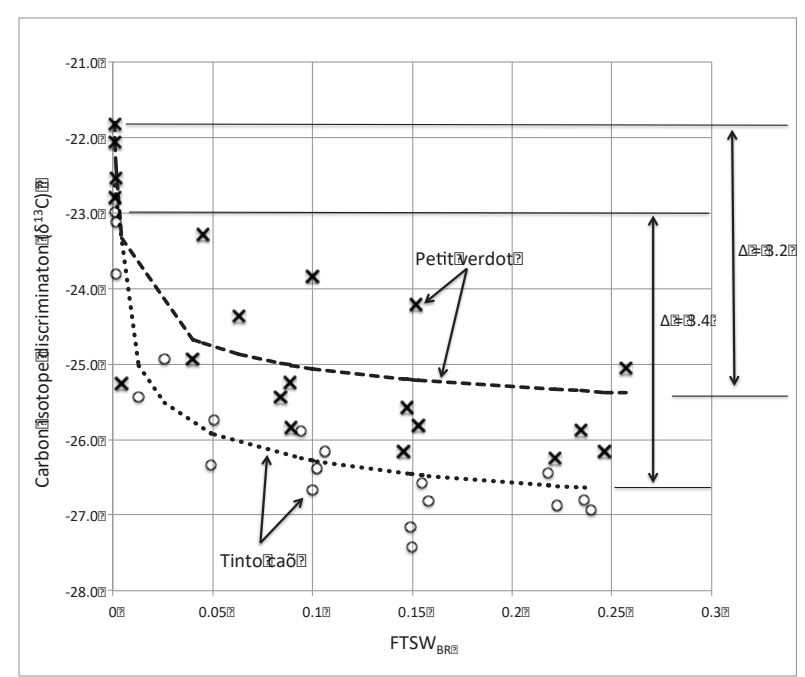

Figure 3. $\delta^{13} \mathrm{C}(\%)$ versus $\mathrm{FTSW}_{\mathrm{BR}}\left(\mathrm{mm}^{3} / \mathrm{mm}^{3}\right)$ with power function regression lines for Tinto Caõ and Petit Verdot and difference $(\Delta)$ between wet and dry years for the two varieties.
Statistically significant differences were also found between some varieties in the response of $\delta^{13} \mathrm{C}$ to changes in soil water content $\left(\mathrm{FTSW}_{\mathrm{BR}}\right)$. For example, a plot of $\delta^{13} \mathrm{C}$ versus FTSW $\mathrm{BR}_{\mathrm{BR}}$ for both Tinto Caõ and Petit Verdot shows similar response curves, but with consistently less negative values (more stomatal closure) seen across all

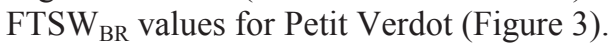

These curves also show the trend of less negative $\delta^{13} \mathrm{C}$ overall in response to decreasing soil water content, with the different varieties demonstrating a good non-linear fit using a power function regression; with all varieties having similar power coefficients as a formula used for estimating soil matrix potential as a function of soil water content [13]. This suggests a the link between increasing soil water potential and associated stomatal closure (vine stress) in response to decreasing soil water content.

The difference in $\delta^{13} \mathrm{C}$ between wet and dry FTSW $_{\mathrm{BR}}$ conditions for the different varieties is also of interest as an indication of stomatal sensitivity to decreasing soil water content. In preliminary analysis many varieties demonstrated a difference in $\delta^{13} \mathrm{C}$ of between 3 to $4 \%$, similar to that shown in Figure 3 for Petit Verdot and Tinto Caõ. But before more definitive conclusions can be made about these varietal differences (and other responses described above), the authors are considering alternative calculations of $\mathrm{FTSW}_{\mathrm{BR}}$ and performing additional statistical analyses.

\subsection{Water potential response}

A plot of average predawn water potential measurements across blocks taken in 2017 versus corresponding water balance model estimates of FTSW shows low vine stress values (none less than $-0.16 \mathrm{MPa}$ ) when FTSW was above 0.4 (Figure 4). After July $28^{\text {th }}$ (moving right to left) predawn water potential dropped significantly as soils dried further past FTSW $=0.4$. This threshold is similar to values reported in the literature $[10,12]$. There were also statistically significant differences between Semillon and three other varieties (Grenache, Petit Verdot, and Cabernet sauvignon) under drier soil conditions later in the year. The cause of this difference is uncertain and being investigated.

Also, a recently proposed method quantifies the relative stomatal closure tendency of different plant species by measuring the area covered by a plot of midday leaf water potential versus predawn leaf water potential across a range of water status, light, and VPD conditions. The relative size of these "hydroscapes" (as determined by a regression line using the most negative midday leaf water potential measurements) is indicative of the relative stomatal sensitivity of a given variety. A larger area indicating less stomatal closure and more variability in plant water potential and a smaller area indicating more stomatal closure and less variability of plant water potential [14]. Unlike other varieties, the water potential measurements for Semillon collected in 2017 began to fill out the hydroscape, although more data is still needed (Figure 5). More midday and predawn leaf water potential with more negative values are needed to fill out that important part of the hydroscape; although the results so far are promising. 


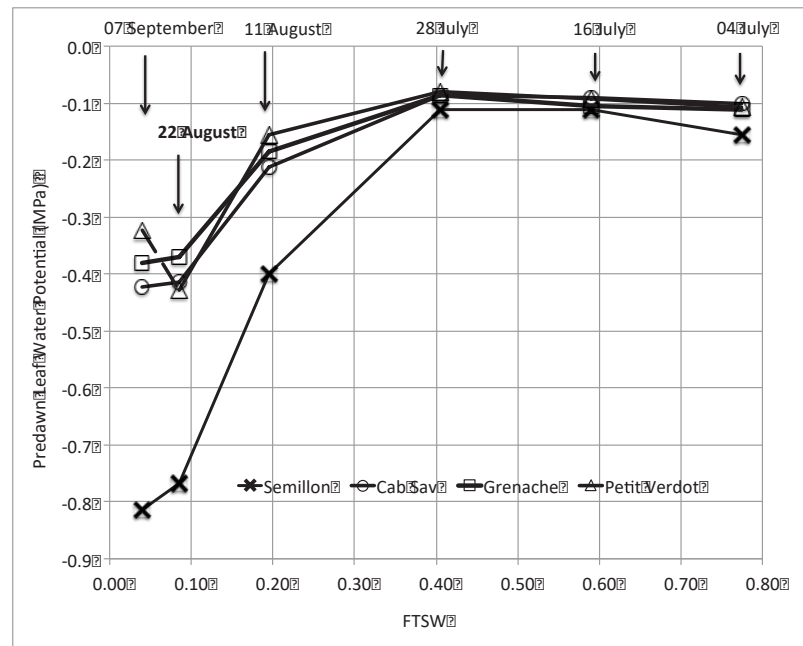

Figure 4. Average predawn leaf water potential (MPa) versus corresponding water balance model estimate of FTSW $\left(\mathrm{mm}^{3} / \mathrm{mm}^{3}\right)$ for measurements taken in 2017 on Semillon, Cabernet sauvignon, Grenache, and Petit verdot.

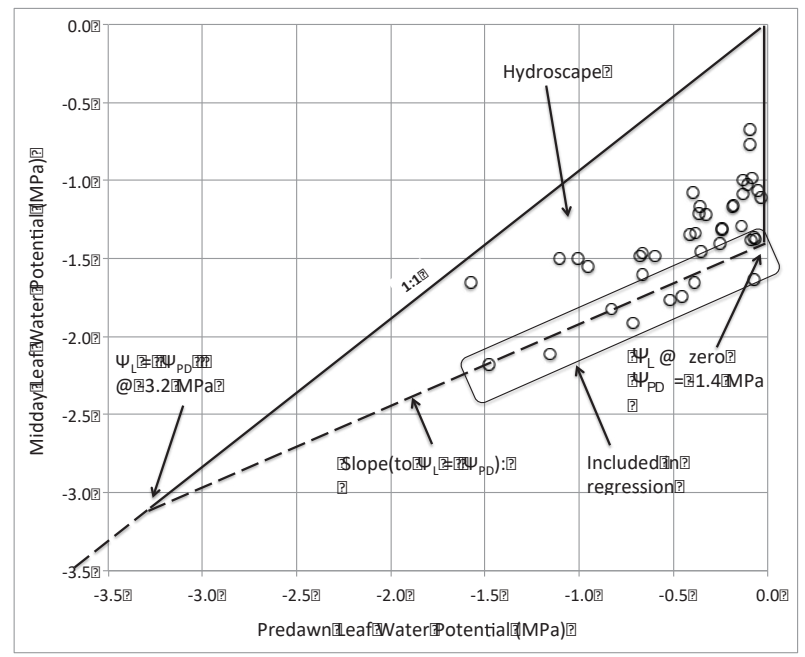

Figure 5. Plot of midday leaf versus predawn leaf water potential measurements (MPa) for Semillon in 2017, including hypothetical and calculated boundaries for the hydroscapes [14].

\section{Discussion and conclusion}

Preliminary analysis of $\delta^{13} \mathrm{C}$ measurements from berry juice collected between 2012 and 2016 suggests greater stomatal closure for all varieties during years of lower average soil water content during the corresponding berry ripening period as estimated with a water balance model using phenology of the individual varieties. Some varieties appear to show significant differences from one another, with the response curves for individual varieties having a non-linear shape similar to those used for estimating soil matrix potential as a function of soil water content. Also, observed differences in $\delta^{13} \mathrm{C}$ between years with wet and dry conditions during berry-ripening ranged between 3 to $4 \%$, but more consideration is being given by the authors to different soil water content averaging methods that might better represent soil water conditions during the time of berry sugar accumulation. Data from subsequent years should also improve the power of statistical determinations of differences between varieties.
Water potential data collected in 2017 from eight varieties finds predawn measurements correlated well with soil water content estimates from a water balance model using the phenology of the individual varieties. The reason for the significantly different response of Semillon is uncertain and being investigated. Also, plots of midday leaf versus predawn leaf water potential measurements show the early development of hydroscape plots that might be useful in further characterizing the stomatal closure behavior of the different varieties in response to changing soil water content. Comparison of the different water potential measurements may give additional insight into stomatal closure response to decreasing soil water content. The authors will also give consideration to effects of vapor pressure deficit as data continues to be collected in subsequent years.

\section{Acknowledgments}

These studies were carried out with support from the French National Research Agency (ANR) under the Investments for the Future Program, within Clusters of Excellence (ANR-10-LABX-45). The VitAdapt Project is also supported by the Conseil Interprofessionnel des Vins de Bordeaux and the Conseil Régional d'Aquitaine.

\section{References}

1. A. Pellegrino, E. Lebon, M. Voltz, J. Wery, Plant and Soil, 266 129-42 (2004).

2. J.S. Sperry, U.G. Hacke, R. Oren, J.P. Comstock, Plant, Cell \& Environment, 25 251-63 (2002).

3. J.P. Gaudillère, C. van Leeuwen, N. Ollat, Journal of Experimental Botany, 53 757-63 (2002).

4. C. van Leeuwen, P. Pieri, P. Vivin, Methodologies and Results in Grapevine Research (Springer: Dordrecht, 2010) 87-106.

5. A. Destrac-Irvine, C. van Leeuwen, CLIMWINE Proceedings, 165-171 (2016).

6. T. Améglio, P. Archer, M. Cohen, C. Valancogne, F-A. Daudet, S. Dayau, P. Cruiziat, Plant and Soil, 207 155-67 (1999).

7. J. Bota, M. Tomás, J. Flexas, H. Medrano, J.M. Escalona, Agricultural Water Management, 164 9199 (2016).

8. A. Bchir, J.M. Escalona, A. Gallé, E. HernándezMontes, I. Tortosa, M. Braham, and H. Medrano, Agricultural Water Management, 167 11-20 (2016).

9. G. Farquhar, Annual Review of Plant Physiology and Plant Molecular Biology, 40 503-37 (1989).

10. L. Krounbi, N. Lazarovitch, Encyclopedia of Agrophysics, (Springer: Dordrecht, 2011) 748-54.

11. X. Choné, C. van Leeuwen, D. Dubourdieu, J.P. Gaudillère, Annals of Botany, 87 477-83 (2001).

12. E. Lebon, V. Dumas, P. Pieri, H.R, Schultz, Functional Plant Biology, 30 699-710 (2003).

13. M.T. van Genuchten, Soil Science Society of America Journal, 44 892-98 (1980).

14. F.C. Meinzer, D.R. Woodruff, D.E. Marias, D.D. Smith, K.A. McCulloh, A.R. Howard, A.L. Magedman, Ecology Letters, 19 1343-52 (2016). 